\title{
The role of heat shock proteins in spinal cord injury
}

\author{
Review article \\ Sangala Jaypal Reddy, M.Ch., D.N.B., Frank La Marca, M.D., and Paul Park, M.D. \\ Department of Neurosurgery, University of Michigan Health System, Ann Arbor, Michigan
}

\begin{abstract}
Heat shock proteins (HSPs) are normal intracellular proteins that are produced in greater amounts when cells are subjected to stress or injury. These proteins have been shown to play a key role in the modulation of the secondary injury that occurs after the initial spinal cord injury (SCI). Heat shock proteins normally act as molecular chaperones and are called protein guardians because they act to repair partially damaged proteins. Normally intracellular, HSPs can also be liberated into the systemic circulation to act as important inflammatory mediators. In the setting of SCI, HSP induction has been shown to be beneficial. These proteins are liberated primarily by acutely stressed microglial, endothelial, and ependymal cells. Heat shock proteins have also been shown to assist in the protection of motor neurons and to prevent chronic inflammation after SCI. In animal models, several experimental drugs have shown neuroprotective effects in the spinal cord and appear to function by modulating HSPs.
\end{abstract}

(DOI: 10.3171/FOC.2008.25.11.E4)

\section{Key Words - heat shock protein - literature review • secondary injury $\quad$ spinal cord injury}

$\mathrm{S}$ PINAL cord injuries have devastating consequences. Whether the primary injury is caused by trauma, ischemia, demyelination, infection, or inflammation, a chain of events is typically triggered that results in further damage to the spinal cord. This chain of events constitutes the secondary injury. ${ }^{45}$ Manipulating the secondary injury is an important technique for mitigating the consequences of the SCI. Many factors are involved in the secondary injury cascade, including HSPs. ${ }^{21,22}$ Heat shock proteins have recently been found to play an important role in the secondary injury phase of SCI., ${ }^{3,5} \mathrm{In}$ this article we review the role of HSPs in SCI and the current research evaluating these proteins in the hopes of improving outcomes after SCI. Although there has been extensive research into HSPs in malignant lesions and neurodegenerative and inherited diseases, in the present study we focus only on the role of HSPs in SCI.

\section{Methods}

Using the search words "heat shock proteins" and "spinal cord injury" we searched the PubMed database. All articles in English were retrieved from 1964 to 2008. Relevant articles were identified and reviewed, and the bibliographies of these articles were also analyzed to

Abbreviations used in this paper: $\mathrm{HSP}=$ heat shock protein; $\mathrm{NBD}=$ nucleotide binding domain; $\mathrm{SCI}=$ spinal cord injury. find other pertinent studies. All articles were reviewed with the primary goal of determining the role of HSPs in SCI.

\section{Results}

Sixty-one articles were identified, only 22 of which dealt with HSPs in SCI. The articles could be broadly classified into 3 types: 1) articles examining the role of HSPs in SCI: $: 5,8,11,15,17,27,28,41,43,44,48-50$ 2) articles examining the manipulation of HSPs to alter outcome after SCI ${ }^{10,25,32,38-42}$ and 3) review articles. ${ }^{5}$ All articles involved only animal models; there were no studies in humans.

\section{Discussion}

\section{Historical Background}

In 1962, Ritossa originally discovered HSPs in isolated heat-shocked Drosophila melanogaster salivary glands where their appearance coincided with chromosomal puffs. In this laboratory, the incubator thermostat was inadvertently set at a high temperature. The following day it was found that the salivary gland chromosomes of the fruit flies exhibited odd puffing patterns on microscopic examination, indicating a novel pattern of gene expression. These chromosomal puffs were specific transcription sites for HSP synthesis. It was not until 1986 that the important functions of HSPs were finally 
understood. At this time, Pelham et al. elucidated the role of HSPs as the cellular chaperone..$^{29}$ However, it was Ellis et al. in 1987 that formally named this function and advanced the concept.

\section{Protein Structure}

As a class, HSPs are among the most highly expressed cellular proteins across all species. ${ }^{24}$ They account for $1-2 \%$ of total protein in unstressed cells. However, when cells are heated or subjected to other stressors, the fraction of HSPs increases to $4-6 \%$ of all cellular proteins. ${ }^{24}$ The HSPs are named according to their molecular weights; for example Hsp60, Hsp70, and Hsp90 (the most widely studied HSPs) refer to families of HSPs that are 60, 70, and $90 \mathrm{kD}$ in size, respectively. Overall, their molecular weights can range $10-150 \mathrm{kD}$. Heat shock protein 90 is the most abundant nonribosomal protein (cytosolic version) and also the most abundant protein in endoplasmic reticulum. ${ }^{24}$ The structures of HSPs of various species have been described in several studies. ${ }^{3,19,20}$ Heat shock protein 70 is the most widely studied. ${ }^{3,9,11,12,14,23,25-27,31,37,42}$ It is also the most temperature-sensitive and highly conserved HSP. Heat shock protein 70 has 2 domains: an $N$-terminal NBD and a substrate binding domain. The 44-kD $N$-terminal NBD has adenosine triphosphatase activity and associates with the Hsp70 cochaperone DnaJ. ${ }^{16}$ These domains are connected by a conserved linker recently shown to be critical for interdomain communication. Heat shock protein 70 has a single peptide binding site with a hydrophobic channel flanked by an arch allowing peptide access. In contrast, Hsp90 has 3 structural domains: 1) an NBD that binds Hsp90 inhibitors and potentially peptides; 2) a middle segment that interacts with client proteins; and 3) the $C$-terminus, implicated in homodimerization. ${ }^{16}$ The characteristics of the important HSPs are listed in Table 1.

\section{Protein Guardians}

The most important function of HSPs is to act as molecular chaperones..$^{30}$ Chaperones aid in the transport of proteins throughout the cell's various compartments. Heat shock proteins are present in cells under normal conditions but are expressed at high levels when exposed to a sudden increase in temperature or other stress. Heat shock proteins stabilize proteins and are involved in the folding of denatured proteins. High temperatures and other stressors such as altered $\mathrm{pH}$ and oxygen deprivation make it more difficult for proteins to form their proper structures and cause already structured proteins to unfold. Left uncorrected, misfolded proteins form aggregates that may eventually kill the cell. Heat shock proteins are induced rapidly in high concentrations to deal with this problem. Any injury that contributes to protein denaturation, including ischemia, heat shock, heavy metals, hypoglycemia, low $\mathrm{pH}$, and disease states appears to produce transcriptional activation of Hsp70. Heat shock protein 70 then acts in concert with Hsp90 and other HSP chaperones to renature the denatured proteins.

Increased expression of HSPs is mediated at multiple levels: mRNA synthesis, mRNA stability, and translation
TABLE 1: Summary of location and function of important HSPs *

\begin{tabular}{|c|c|c|}
\hline HSP & $\begin{array}{l}\text { Intracellular } \\
\text { Location }\end{array}$ & Proposed Function \\
\hline Hsp27 & cytosol \& nucleus & antiapoptotic; microfilament stabilization \\
\hline Hsp60 & mitochondria & $\begin{array}{l}\text { involved in protein folding after post- } \\
\text { translational import to the mitochondria; } \\
\text { prevents aggregation of denatured } \\
\text { proteins; proapoptotic }\end{array}$ \\
\hline Hsp70 & $\begin{array}{l}\text { cytosol, ER, \& } \\
\text { mitochondria }\end{array}$ & $\begin{array}{l}\text { molecular chaperone, thermotolerance, } \\
\text { antiapoptotic }\end{array}$ \\
\hline Hsp90 & $\begin{array}{l}\text { cytosol, ER, \& } \\
\text { nucleus }\end{array}$ & $\begin{array}{l}\text { maintains steroid receptors \& transcrip- } \\
\text { tion factors, antiapoptotic }\end{array}$ \\
\hline Hsp104 & cytosol & protein folding \\
\hline
\end{tabular}

* ER = endoplasmic reticulum.

efficiency. The induction of HSPs is regulated by transacting heat shock factors and a cis-acting heat shock element present at the promoter region of heat shock genes. ${ }^{24}$ Once synthesized, these HSPs bind to the denatured protein and prevent aggregation. Some HSPs, such as Hsp104, are able to rescue already aggregated proteins. ${ }^{35}$ Because of these functions, HSPs are aptly called the "guardians of proteins." ${ }^{30}$

Although these proteins are normally intracellular, HSPs can be liberated into the systemic circulation after cell necrosis. Systemic HSPs are some of the most effective inflammatory mediators and are called chaperokines or extracellular HSPs. ${ }^{1}$

\section{Heat Shock Proteins and SCI}

Significant advances have been made in understanding the action of HSPs in SCI in animal models. In these studies, the most common model used for evaluation was an ischemic SCI model produced by clamping the thoracic aorta. ${ }^{4,34}$ The most common HSP studied was Hsp70.

Based on these animal studies, it is clear that HSPs are important modulators of SCI. In SCI the primary injury is known to produce a state of hyperexcitability due to intracellular entry of calcium, liberation of free radicals, and production of excitatory neurotransmitters including glutamate, lactate, pyruvate, and aspartate. All together, these events trigger what is known as the secondary injury cascade..$^{45}$ This cascade is further magnified by the liberation of nitric oxide and adenosine in a delayed fashion. Excitotoxicity triggers a glial reactive response characterized by the release of proinflammatory cytokines, such as tumor necrosis factor $-\alpha$ and interleukin- $1 \beta$ that are mainly produced by microglial and endothelial cells. The production of cytokines by microglial cells leads to concomitant upregulation of Hsp70. As a chaperone, Hsp70 protects cells from proteotoxic stress through a variety of "holding and folding" pathways that prevent protein denaturation and the progression of lethal aggregation cascades in cells, thus preventing cell death both through necrotic and apoptotic pathways. ${ }^{24}$ However, the liberated extracellular HSPs can trigger a systemic inflammatory response. ${ }^{6}$ 
Other studies using an acute traumatic SCI model in rats have provided evidence that HSPs probably play a role in SCI. Using DNA microarray technology, Song et al. ${ }^{43}$ demonstrated that Hsp70 is among the most frequently produced proteins after SCI. In a similar model using gene expression, Tachibana and coworkers ${ }^{44}$ found that Hsp27 showed a $>2$-fold increase 24 hours after SCI.

The role of HSPs is complex: they can be proinflammatory and yet they may also have significant antiinflammatory and cytoprotective actions. ${ }^{7,37}$ Studies have shown that HSPs have a multifaceted modulatory role in inflammation. These proteins have been shown to promote inflammation initially and then exert an antiinflammatory effect, thereby limiting chronic sequelae. In fact an elevation in autologous extracellular Hsp70 has been shown to protect against a wide range of chronic inflammatory diseases including arthritis, atherosclerosis, and Type 1 diabetes. It may be that extracellular HSPs in the cerebrospinal fluid inhibit the development of chronic inflammatory disease after acute injury to the central nervous system.

Unlike microglial and ependymal cells, motor neurons express very low levels of HSPs in the setting of acute SCI. ${ }^{12}$ Heat shock proteins, however, have been shown to be directly cytoprotective of motor neurons. ${ }^{37}$ Robinson et al. ${ }^{37}$ have demonstrated the dependence of motor neurons on circulating extracellular HSPs. Considering the size of motor neurons and the metabolic demands placed on them, the authors hypothesized that motor neurons are only capable of synthesizing amounts of Hsp70 necessary for maintenance of cell function and survival and did not appear to increase production in response to the greater demands of stressful stimuli. The extracellular Hsp70 derived from other cell types may compensate for this deficit. It is conceivable, therefore, that in situations of environmental stress, the amount of extracellular Hsp70 available to motor neurons becomes limited as utilization of these proteins is increased in the surrounding cells. This situation would then place the motor neurons in a position of insufficient access to Hsp70, rendering them more susceptible to damage and death than if Hsp70 were more abundant. Such results suggest a critical role for extracellular Hsp70 in promoting motor neuron survival. ${ }^{46}$

Rajdev et al., ${ }^{36}$ Yenari et al., ${ }^{51}$ and Kelly et al. ${ }^{18}$ have also shown that Hsp70 serves a cytoprotective function and confers ischemic tolerance in the brain when overexpressed by a transgene or viral vector. Similarly, Cizkova and associates ${ }^{8}$ have demonstrated that sublethal cellular stress mediated by hyperthermia or mild transient ischemia can also elevate Hsp70 levels and confer ischemic tolerance in the spinal cord. In other animal studies, the spinal cord was noted to have improved tolerance of ischemic effects after ischemic preconditioning. ${ }^{13,33,38}$ Some authors have noted that ischemic preconditioning may have a beneficial effect through the increased synthesis of HSPs. ${ }^{4,13,34}$ Perdrizet and colleagues ${ }^{34}$ found that preoperative stress conditioning in the form of whole body hyperthermia or tin(II) chloride administration and recovery can prevent paralysis in a rabbit model of aortic surgery. This ischemic spinal cord protection is associated with an increased level of stress proteins within the spinal cord (such as Hsp70) and in other organs. These changes in function and stress protein synthesis were associated with preservation of the histological morphology of the spinal cord. In another study, Matsumoto and coworkers ${ }^{26}$ elucidated the temporal efficacy of ischemic pretreatment in the spinal cord: the protective effect was apparent 4 days after pretreatment. In their study the amount of Hsp70 in the cytoplasm did not explain the temporal profile of ischemic tolerance and they hypothesized that nuclear Hsp70 might play a role in the acquisition of ischemic tolerance.

Asea at al. ${ }^{2}$ have reported on the expanded role of Hsp70 and have ascribed novel functions to the Hsp70 protein depending on its localization. Surface-bound Hsp70 specifically activate natural killer cells while Hsp70 released into the extracellular milieu specifically binds to TLR2 and TLR4 on antigen-presenting cells and exerts immunoregulatory effects including upregulation of adhesion molecules and costimulatory molecule expression as well ascytokine and chemokine release, a process known as the "chaperokine" activity of Hsp70. The chaperokine activities of HSPs have been shown to play an important role in host protection against pathogenic infections.

The authors of numerous studies have suggested that the beneficial effects of various drugs in SCI are due to modulation of HSPs. Shin et al. ${ }^{42}$ demonstrated that cyclosporin A reduces neurological injury in a rabbit model of 25-minute spinal cord ischemia. They concluded that this neuroprotective effect against ischemia was related to overexpression of neural nitric oxide synthetase and Hsp70. The neuroprotective effect was more evident on postoperative Day 7 than on Day 2, indicating the role of HSPs in modulating secondary injury. Park and associates $^{32}$ demonstrated improved outcome after SCI in rats pretreated with peroxisome proliferator-activated receptor inhibitors. They also hypothesized that this neuroprotective action was partially mediated by the upregulation of HSPs. Guzman-Lenis et al. ${ }^{12}$ examined on the neuroprotective effects of an experimental drug called FK506 (tacrolimus) and concluded that the drug's beneficial effects were due to Hsp70 downregulation. Lee and colleagues ${ }^{23}$ working in a rat SCI injury model also postulated that the neuroprotective action of bupivacaine and hypothermia in SCI was due to HSP downregulation. Sharma and colleagues ${ }^{39}$ reported that the experimental drug H-290/51 induced neuroprotection by preventing the upregulation of HSPs that occurs after focal SCI. Their results suggested an important contribution of the oxidative stress response in HSP induction, microvascular permeability disturbances, edema formation, and cell injury after SCI. Waza et al. ${ }^{47}$ reported similar results indicating a neuroprotective effect with inhibition of HSPs. They demonstrated that inhibition of Hsp90 by 17-AAG, a potent Hsp90 inhibitor, ameliorated motor impairment, and attenuated motor neuron degeneration in a mouse model of spinal and bulbar muscular atrophy.

Based on these studies, both up- and downregulation of HSPs appear to have neuroprotective effects. Such contradictory findings probably reflect the complex role of HSPs in modulating secondary injury after SCI. Similar to other inflammatory mediators, HSPs probably have 
both beneficial and deleterious effects in SCI. Given the involvement of HSPs in SCI, investigators have even used HSP levels as a measure of SCI. ${ }^{39}$

\section{Conclusions}

At present our understanding of the role of HSPs in SCI is limited. There is a preponderance of evidence in animal studies suggesting that HSPs are extremely important in modulating inflammation and are aptly referred to as the guardians of proteins due to their ability to stabilize proteins. Heat shock proteins are mainly synthesized by microglial, ependymal, and endothelial cells after SCI and seem protective of motor neurons. Certain experimental drugs that have shown to be neuroprotective to the spinal cord appear to function by modulating HSPs. Further experiments elucidating the exact role of HSPs in SCI may lead to clinically useful improvements in outcomes.

\section{References}

1. Asea A, Kabingu E, Stevenson MA, Calderwood SK: HSP70 peptidembearing and peptide-negative preparations act as chaperokines. Cell Stress Chaperones 5:425-431, 2000

2. Asea A, Rehli M, Kabingu E, Boch JA, Bare O, Auron PE, et al: Novel signal transduction pathway utilized by extracellular HSP70: role of toll-like receptor (TLR) 2 and TLR4. J Biol Chem 277:15028-15034, 2002

3. Awad H, Suntres Z, Heijmans J, Smeak D, Bergdall-Costell V, Christofi FL, et al: Intracellular and extracellular expression of the major inducible $70 \mathrm{kDa}$ heat shock protein in experimental ischemia-reperfusion injury of the spinal cord. Exp Neurol 212:275-284, 2008

4. Basaran M, Kafali E, Sayin O, Ugurlucan M, Us MH, Bayindir C, et al: Heat stress increases the effectiveness of early ischemic preconditioning in spinal cord protection. Eur $\mathbf{J}$ Cardiothorac Surg 28:467-472, 2005

5. Brown IR: Heat shock proteins and protection of the nervous system. Ann N Y Acad Sci 1113:147-158, 2007

6. Campisi J, Fleshner M: Role of extracellular HSP72 in acute stress-induced potentiation of innate immunity in active rats. J Appl Physiol 94:43-52, 2003

7. Chen Y, Voegeli TS, Liu PP, Noble EG, Currie RW: Heat shock paradox and a new role of heat shock proteins and their receptors as anti-inflammation targets. Inflamm Allergy Drug Targets 6:91-100, 2007

8. Cizkova D, Carmel JB, Yamamoto K, Kakinohana O, Sun D, Hart RP, et al: Characterization of spinal HSP72 induction and development of ischemic tolerance after spinal ischemia in rats. Exp Neurol 185:97-108, 2004

9. Cizkova D, Lukacova N, Marsala M, Kafka J, Lukac I, Jergova $\mathrm{S}$, et al: Experimental cauda equina compression induces HSP70 synthesis in dog. Physiol Res 54:349-356, 2005

10. Fujiki M, Furukawa Y, Kobayashi H, Abe T, Ishii K, Uchida $\mathrm{S}$, et al: Geranylgeranylacetone limits secondary injury, neuronal death, and progressive necrosis and cavitation after spinal cord injury. Brain Res 1053:175-184, 2005

11. Gower DJ, Hollman C, Lee KS, Tytell M: Spinal cord injury and the stress protein response. J Neurosurg 70:605-611, 1989

12. Guzman-Lenis MS, Vallejo C, Navarro X, Casas C: Analysis of FK506-mediated protection in an organotypic model of spinal cord damage: heat shock protein 70 levels are modulated in microglial cells. Neuroscience 155:104-113, 2008

13. Haveman J, Sminia P, Wondergem J, van der Zee J, Hulshof
MC: Effects of hyperthermia on the central nervous system: what was learnt from animal studies? Int J Hyperthermia 21:473-487, 2005

14. Hecker JG, Sundram H, Zou S, Praestgaard A, Bavaria JE, Ramchandren S, et al: Heat shock proteins HSP70 and HSP27 in the cerebral spinal fluid of patients undergoing thoracic aneurysm repair correlate with the probability of postoperative paralysis. Cell Stress Chaperones [epub ahead of print], 2008

15. Huey KA, Roy RR, Zhong H, Lullo C: Time-dependent changes in caspase- 3 activity and heat shock protein 25 after spinal cord transection in adult rats. Exp Physiol 93:415425, 2008

16. Javid B, MacAry PA, Lehner PJ: Structure and function: heat shock proteins and adaptive immunity. J Immunol 179:20352040, 2007

17. Kang SK, So HH, Moon YS, Kim CH: Proteomic analysis of injured spinal cord tissue proteins using 2-DE and MALDITOF MS. Proteomics 6:2797-2812, 2006

18. Kelly S, Zhang ZJ, Zhao H, Xu L, Giffard RG, Sapolsky RM, et al: Gene transfer of HSP72 protects cornu ammonis 1 region of the hippocampus neurons from global ischemia: influence of Bcl-2. Ann Neurol 52:160-167, 2002

19. Kennaway CK, Benesch JL, Gohlke U, Wang L, Robinson $\mathrm{CV}$, Orlova EV, et al: Dodecameric structure of the small heat shock protein Acrl from Mycobacterium tuberculosis. J Biol Chem 280:33419-33425, 2005

20. Kumar R, Pavithra SR, Tatu U: Three-dimensional structure of heat shock protein 90 from Plasmodium falciparum: molecular modelling approach to rational drug design against malaria. J Biosci 32:531-536, 2007

21. Kunz S, Tegeder I, Coste O, Marian C, Pfenninger A, Corvey $\mathrm{C}$, et al: Comparative proteomic analysis of the rat spinal cord in inflammatory and neuropathic pain models. Neurosci Lett 381:289-293, 2005

22. Kwon BK, Tetzlaff W, Grauer JN, Beiner J, Vaccaro AR: Pathophysiology and pharmacologic treatment of acute spinal cord injury. Spine J 4:451-464, 2004

23. Lee JR, Han SM, Leem JG, Hwang SJ: Effects of intrathecal bupivacaine in conjunction with hypothermia on neuronal protection against transient spinal cord ischemia in rats. Acta Anaesthesiol Scand 51:60-67, 2007

24. Lindquist S, Craig EA: The heat-shock proteins. Annu Rev Genet 22:631-677, 1988

25. Manzerra P, Brown IR: Expression of heat shock genes (hsp70) in the rabbit spinal cord: localization of constitutive and hyperthermia-inducible mRNA species. J Neurosci Res 31:606-615, 1992

26. Matsumoto M, Ohtake K, Wakamatsu H, Oka S, Kiyoshima T, Nakakimura K, et al: The time course of acquisition of ischemic tolerance and induction of heat shock protein 70 after a brief period of ischemia in the spinal cord in rabbits. Anesth Analg 92:418-423, 2001

27. Mautes AE, Noble LJ: Co-induction of HSP70 and heme oxygenase-1 in macrophages and glia after spinal cord contusion in the rat. Brain Res 883:233-237, 2000

28. McIntosh TK, Raghupathi R: Cell stress genes and acute CNS injury. Neuropathol Appl Neurobiol 21:477-479, 1995

29. Morange M: What history tells us II. The discovery of chaperone function. J Biosci 30:461-464, 2005

30. Ohtsuka K, Suzuki T: Roles of molecular chaperones in the nervous system. Brain Res Bull 53:141-146, 2000

31. Pan F, Chen AM, Guo FJ, Zhu CL: [Effect of tacrolimus on apoptosis and expression of heat shock protein 70 after acute spinal cord injury in rats.] Zhonghua Wai Ke Za Zhi 44:1708-1712, 2006 (Chinese)

32. Park SW, Yi JH, Miranpuri G, Satriotomo I, Bowen K, Resnick DK, et al: Thiazolidinedione class of peroxisome proliferatoractivated receptor gamma agonists prevents neuronal damage, 


\section{Heat shock proteins}

motor dysfunction, myelin loss, neuropathic pain, and inflammation after spinal cord injury in adult rats. J Pharmacol Exp Ther 320:1002-1012, 2007

33. Perdrizet GA: Heat shock and tissue protection. New Horiz 3:312-320, 1995

34. Perdrizet GA, Lena CJ, Shapiro DS, Rewinski MJ: Preoperative stress conditioning prevents paralysis after experimental aortic surgery: increased heat shock protein content is associated with ischemic tolerance of the spinal cord. J Thorac Cardiovasc Surg 124:162-170, 2002

35. Perrin V, Regulier E, Abbas-Terki T, Hassig R, Brouillet E, Aebischer P, et al: Neuroprotection by Hsp104 and Hsp27 in lentiviral-based rat models of Huntington's disease. Mol Ther 15:903-911, 2007

36. Rajdev S, Hara K, Kokubo Y, Mestril R, Dillmann W, Weinstein PR, et al: Mice overexpressing rat heat shock protein 70 are protected against cerebral infarction. Ann Neurol 47:782-791, 2000

37. Robinson MB, Tidwell JL, Gould T, Taylor AR, Newbern JM, Graves J, et al: Extracellular heat shock protein 70: a critical component for motoneuron survival. J Neurosci 25:97359745,2005

38. Sakurai M, Aoki M, Abe K, Sadahiro M, Tabayashi K: Selective motor neuron death and heat shock protein induction after spinal cord ischemia in rabbits. J Thorac Cardiovasc Surg 113:159-164, 1997

39. Sharma HS, Gordh T, Wiklund L, Mohanty S, Sjoquist PO: Spinal cord injury induced heat shock protein expression is reduced by an antioxidant compound H-290/51. An experimental study using light and electron microscopy in the rat. $\mathbf{J}$ Neural Transm 113:521-536, 2006

40. Sharma HS, Olsson Y, Westman J: A serotonin synthesis inhibitor, p-chlorophenylalanine reduces the heat shock protein response following trauma to the spinal cord: an immunohistochemical and ultrastructural study in the rat. Neurosci Res 21:241-249, 1995

41. Sharma HS, Westman J: Prostaglandins modulate constitutive isoform of heat shock protein $(72 \mathrm{kD})$ response following trauma to the rat spinal cord. Acta Neurochir Suppl (Wien) 70:134-137, 1997

42. Shin YC, Choi KY, Kim WG: Cyclosporin A has a protec- tive effect with induced upregulation of Hsp70 and nNOS on severe spinal cord ischemic injury in rabbits. J Invest Surg 20:113-120, 2007

43. Song G, Cechvala C, Resnick DK, Dempsey RJ, Rao VL: GeneChip analysis after acute spinal cord injury in rat. J Neurochem 79:804-815, 2001

44. Tachibana T, Noguchi K, Ruda MA: Analysis of gene expression following spinal cord injury in rat using complementary DNA microarray. Neurosci Lett 327:133-137, 2002

45. Tator $\mathrm{CH}$, Fehlings MG: Review of the secondary injury theory of acute spinal cord trauma with emphasis on vascular mechanisms. J Neurosurg 75:15-26, 1991

46. Tytell M: Release of heat shock proteins (Hsps) and the effects of extracellular Hsps on neural cells and tissues. Int J Hyperthermia 21:445-455, 2005

47. Waza M, Adachi H, Katsuno M, Minamiyama M, Sang C, Tanaka F, et al: 17-AAG, an Hsp90 inhibitor, ameliorates polyglutamine-mediated motor neuron degeneration. Nat Med 11:1088-1095, 2005

48. Willoughby DS, Priest JW, Nelson M: Expression of the stress proteins, ubiquitin, heat shock protein 72 , and myofibrillar protein content after 12 weeks of leg cycling in persons with spinal cord injury. Arch Phys Med Rehabil 83:649-654, 2002

49. Winkler T, Sharma HS, Stalberg E, Badgaiyan RD: Neurotrophic factors attenuate alterations in spinal cord evoked potentials and edema formation following trauma to the rat spinal cord. Acta Neurochir Suppl 76:291-296, 2000

50. Xia H, Ikata T, Katoh S, Rokutan K, Saito S, Kawai T, et al: Whole body hyperthermia selectively induces heat shock protein 72 in neurons of the rat spinal cord. Neurosci Lett 258:151-154, 1998

51. Yenari MA, Sapolsky RM: Gene therapy in neurological disease. Methods Mol Med 104:75-88, 2005

Manuscript submitted July 15, 2008.

Accepted August 14, 2008.

Address correspondence to: Paul Park, M.D., Department of Neurosurgery, University of Michigan Health System, 1500 East Medical Center Drive, Room 3552, Taubman Center, Ann Arbor, Michigan 48109-5338. email: ppark@umich.edu. 